\title{
A comparison of four major antigens in five human and several animal strains of ureaplasmas
}

\author{
D. THIRKELL, ALISON D. MYLES and D. TAYLOR-ROBINSON*
}

Department of Biochemistry and Microbiology, University of St Andrews, Irvine Building, North Street, St Andrews, Fife, KY16 9AL, and "Division of Sexually Transmitted Diseases, Clinical Research Centre, Watford Road, Harrow, Middlesex

\begin{abstract}
Summary. A comparison of the antigens of single representatives of five serotypes of Ureaplasma urealyticum, of three strains of $U$. diversum and of single ureaplasmal strains from four other animal hosts was performed by immunoblotting with monoclonal antibodies and a urease 'enzyme-catch test'. The $U$. urealyticum serotype 8-specific, surface-expressed, 96-Kda antigen was not found in any of the strains of non-human origin. Differences in the distribution of 16- and 17-Kda antigens were also seen, not only between seroclusters $\mathrm{A}$ and $\mathrm{B}$ of $U$. urealyticum, but also with respect to animal strains. Five distinct epitopes were expressed on the urease from $U$. urealyticum and from chimpanzee ureaplasmal strains, but between one and three of these epitopes were either poorly expressed or not detected on the urease from the other animal strains. Apart from lacking the 96-Kda antigen of U. urealyticum serotype 8 , chimpanzee strains gave results similar to those obtained with serocluster A of $U$. urealyticum. The results with the marmoset strain differed from those of all other non-human strains.
\end{abstract}

\section{Introduction}

Ureaplasmas are unique among the mycoplasmas in their ability to hydrolyse urea. Ureaplasma urealyticum, isolated from man, has been differentiated into 14 serotypes by means of a scheme involving a modified metabolism-inhibition test and a colony indirect epifluorescent test. ${ }^{1}$ These 14 serotypes have also been grouped into two seroclusters-Group A, serotypes 2, 4, 5, 7, 8, 9, 10, 11, 12 and 13 and Group B, serotypes 1, 3, 6 and 14-by various techniques. ${ }^{2,3}$

In animals, strains isolated from cattle have been classified as $U$. diversum, of which some 25 strains have been differentiated into three separate groups by an indirect immunofluorescence test. ${ }^{4}$ The largest of these three groups has been further subdivided into three subgroups on the basis of oneand two-dimensional SDS-PAGE. ${ }^{5}$ Ureaplasmas have also been isolated from non-human primates and canine species and in each case they appear to form four distinct serological groups. ${ }^{6}$ Caprine, feline and ovine ureaplasmas form two serogroups whereas those isolated from birds form one serogroup with two seroclusters. ${ }^{6}$

Received 14 Aug. 1989; revised version accepted 5 Dec. 1989.
The urease and both serotype 8- and seroclusterspecific antigens of $U$. urealyticum have been described and monoclonal antibodies (MAbs) against these proteins have been developed. ${ }^{3,7}$ In this study, the MAbs have been used to examine whether major antigens of $U$. urealyticum are similarly expressed in some ureaplasmal strains of chimpanzee, bovine, ovine, canine, feline and marmoset origin.

\section{Materials and methods}

\section{Ureaplasmal strains}

The following were used: $U$. urealyticum of serotypes 1 (T7), 5 (NIH5), 8 (T960), 9 (9-Vancouver) and 13 (JsL6) (serotypes 5, 9 and 13 were provided by Professor J. Robertson, University of Edmonton, Alberta, Canada); $U$. diversum (T44) and ovine (7860/1) and bovine (E172/ 1) field isolates, provided by $\mathrm{Dr}$ G. E. Jones, Moredun Research Institute, Edinburgh; and ureaplasmal strains of canine (9255.E6), feline (8638.B9), marmoset (13583.F8) and chimpanzee (13838, 13849, 13863, 13882 and 13992) origin. The chimpanzee strains were provided by Dr M. F. Barile; they were isolated from the urethras of male animals or the vaginas of females in a breeding colony of chimpanzees at the Primate Research Institute, Holloman Air Force Base, N M, USA. Strain 13863 was 
freed of contaminating Mycoplasma hominis by 4 passages through medium containing lincomycin (Sigma) $50 \mathrm{mg}$ / L.

\section{Medium and cell production}

Ureaplasmas were grown in medium containing PPLO Broth (Difco) 70\% v/v, horse serum (NBL) 20\% $\mathrm{v} / \mathrm{v}$ and fresh yeast extract $2.5 \% \mathrm{w} / \mathrm{v}$. The medium also contained urea $0.1 \%$, phenol red $0.005 \%$ and penicillin $\mathrm{G}$ $10^{3} \mathrm{IU} / \mathrm{ml}$, and had an initial $\mathrm{pH}$ of $6 \cdot 0$. Cultures were incubated at $37^{\circ} \mathrm{C}$ until a pH of 7.6 was reached, after which the organisms were harvested by centrifugation $(25000 \mathrm{~g}, 20 \mathrm{~min})$. The pellets were washed once in Dulbecco's phosphate-buffered saline 'A' $(\mathrm{PBS})^{8}$ and the final pellets were suspended in PBS and used directly or after storage at $-70^{\circ} \mathrm{C}$.

\section{Antibody preparation}

For MAbs, BALB/c mice were immunised with purified urease or with alum-precipitated ${ }^{9}$ sonicated washed cells of $U$. urealyticum, serotype 8, as described previously, ${ }^{3,7,10}$ Of the MAbs available, the following were used in this study: (i) anti-96-Kda antigen-UU8/ 5 , UU8/29, UU8/32 and UU8/37, each of which recognises a distinct epitope on this $U$. urealyticum serotype 8-specific antigen; (ii) anti-16/17-Kda antigenUU8/39 which differentiates the seroclusters of U. urealyticum; (iii) anti-urease-UU8/12, UU8/16, UU8/17 and UU8/25, which recognise distinct epitopes on the enzyme, and UU8/1, which may or may not recognise the same epitope as UU8/17. ${ }^{11}$

Screening for antibodies was by radioimmune-assay with ${ }^{125}$ I-labelled Protein A and, where appropriate, the urease 'enzyme-catch test'. ${ }^{10}$ Briefly, in the latter test, active urease from fresh $U$. urealyticum cell lysate was trapped in wells of a 96-well microtitration plate precoated with growth medium from the anti-urease hybridoma cells; after incubation with $15 \mathrm{mM}$ urea, colour was developed with Bertholet reagents.

\section{SDS-PAGE}

The method of Russell and Blair ${ }^{12}$ was followed, with either $7.5 \% \mathrm{w} / \mathrm{v}$ or $15 \% \mathrm{w} / \mathrm{v}$ polyacrylamide slab gels. Except for evaluation of 'native' urease, samples for electrophoresis were boiled for $2 \mathrm{~min}$ after the addition of an equal volume of a solution containing $5 \mathrm{M}$ urea, SDS $2 \% \mathrm{w} / \mathrm{v}, 3.5 \mathrm{M} \beta$-mercaptoethanol and bromophenol blue $0.1 \%$. For 'native' urease, samples for electrophoresis were mixed with glycerol ( 1 part sample: 3 parts glycerol) and without heat treatment. These samples were electrophoresed in two ways - one with SDS both in the gel and in the buffer, and one without SDS in either the gel or the buffer. Apparent molecular masses $\left(\mathbf{M}_{\mathrm{r}}\right)$ were determined, where appropriate, by comparison with protein standards of known $\mathbf{M}_{\mathrm{r}}$ (Bethesda Research Laboratories) after staining of gels with Coomassie Blue or staining of electroblots with naphthalene black.
Non-denaturing PAGE. Polyacrylamide $7 \cdot 5 \% \mathrm{w} / \mathrm{v}$ gels were prepared as above, except that SDS was omitted from both the gels and the buffer. Samples were mixed with glycerol as before and received no heat treatment.

\section{Detection of urease activity on the gels}

The gels containing SDS were thoroughly washed with PBS containing Nonidet P40 (Sigma) $0 \cdot 2 \% \mathrm{v} / \mathrm{v}$ (PBS-N) before staining. The gels were rocked for $20 \mathrm{~min}$ in $50 \mathrm{mM}$ sodium acetate buffer, pH 5.0, containing $1 \mathrm{~mm}$ EDTA, and for a further $20 \mathrm{~min}$ in $20 \mathrm{~mm}$ sodium acetate buffer, pH 5.0, containing $1 \mathrm{~mm}$ EDTA. After incubation ( $3 \mathrm{~min}$, $20^{\circ} \mathrm{C}$ ) in $1 \mathrm{~mm}$ EDTA containing urea $1.5 \% \mathrm{w} / \mathrm{v}$, the gels were rinsed in distilled water and rocked in $0.1 \mathrm{M}$ lead acetate. ${ }^{13}$

\section{Immunoblotting}

Transfer of polypeptides from polyacrylamide gels to nitrocellulose sheets was performed on an Ancos Model A semi-dry electroblotter according to the instructions of the supplier. The blots were blocked with bovine serum albumin $3 \% \mathrm{w} / \mathrm{v}\left(30 \mathrm{~min}, 20^{\circ} \mathrm{C}\right)$, washed three times for a total of $30 \mathrm{~min}$ with PBS-N and then incubated with MAbs (diluted 1 in 500 in PBS-N: growth medium $50: 50 \mathrm{v} / \mathrm{v}$ ) for $1 \mathrm{~h}$ at $37^{\circ} \mathrm{C}$. After washing three times with PBS-N, approximately $10^{6} \mathrm{cpm}$ of ${ }^{125}$ I-labelled Protein A (45 mCi.mg/ml; Amersham) was added and after incubation $\left(1 \mathrm{~h}, 20^{\circ} \mathrm{C}\right)$ and extensive washing with PBS-N, the nitrocellulose sheet was subjected to autoradiography with X-ray film (Fuji-RX) and a Philips fast tungstate intensifying screen. The films were developed after overnight exposure.

\section{Results}

In tests with all 14 serotypes of $U$. urealyticum, it has been reported previously ${ }^{3}$ that the $96-\mathrm{Kda}$ antigen is serotype 8-specific and that this antigen expresses a minimum of four distinct epitopes. With a MAb that recognised each of the four epitopes, the 96-Kda antigen was not detected in any of the non-human strains by immunoblotting or, as before, ${ }^{3}$ in $U$. urealyticum strains of serotypes $1,5,9$ or 13 (data not shown). A typical result is shown in the composite fig. 1 which is derived from two separate immunoblots, each of which had positive and negative tracks and $M_{r}$ markers.

\section{Distribution of the 16/17-Kda antigens}

MAb UU8/39 had been shown previously to react with serotypes of $U$. urealyticum in an interesting manner. ${ }^{3}$ Thus, as shown by the immunoblotting results (fig. 2), it recognised both the 16and 17-Kda antigens of serotype 8 in serocluster $A$ of $U$. urealyticum, but only the $17-\mathrm{Kda}$ antigen in 


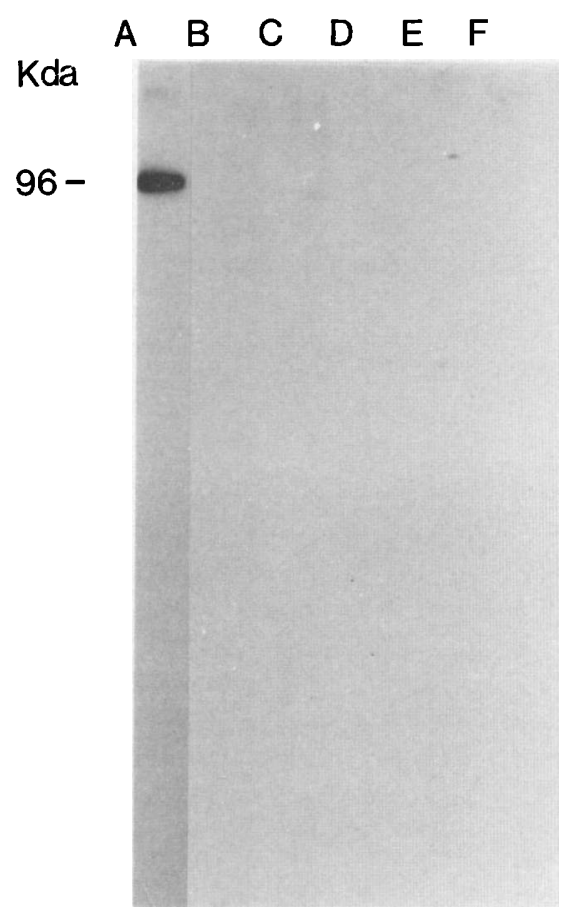

Fig. 1. Immunoblots of ureaplasmal strains probed with $\mathrm{MAb}$ UU8/29 and ${ }^{125}$ I-labelled Protein A. Lane A, U. urealyticum serotype 8 ; B, chimpanzee (13863); C, $U$. diversum (T44); D, canine; $\mathbf{E}$, feline; $\mathbf{F}$, marmoset. SDS-PAGE was performed on a $15 \% \mathrm{w} / \mathrm{v}$ gel.

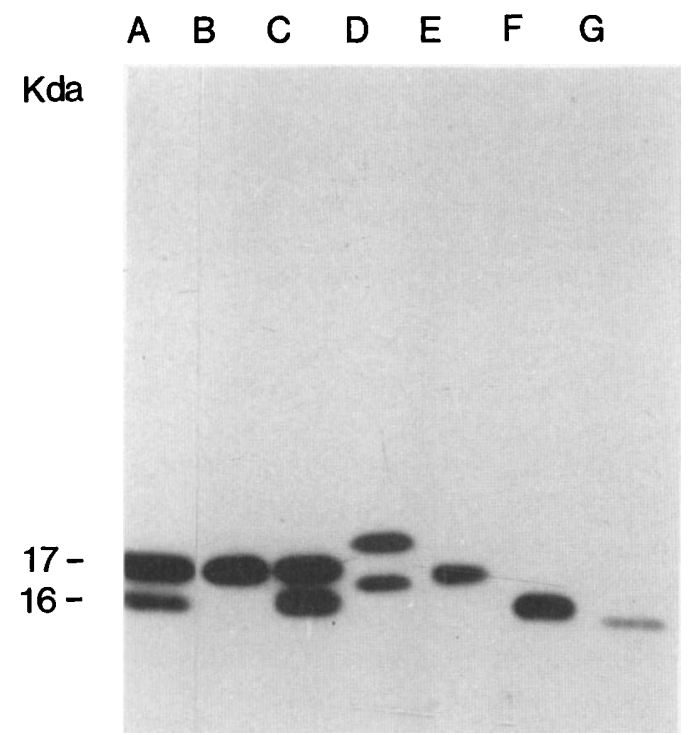

Fig. 2. Immunoblots of ureaplasmal strains with MAb UU8/39 and ${ }^{125}$ I-labelled Protein A. Lane A, U. urealyticum serotype 8; B, $U$. urealyticum serotype 1 ; C, chimpanzee (13863); D, canine; E, marmoset; F, $U$. diversum (T44); G, feline. SDS-PAGE was performed on a $15 \%(\mathrm{w} / \mathrm{v})$ gel. (Lane $A$, from the same gel and immunoblot, has been repositioned for easier comparison.) serotype 1 of serocluster $B$. The results obtained by immunoblotting of the non-human ureaplasmal strains with this MAb are also shown in fig. 2. It is noteworthy that only the $16-\mathrm{Kda}$ antigen was recognised in the feline strain and in the three species of $U$. diversum (strain T44 shown) and, as for $U$. urealyticum serocluster $B$ (here and in a previous study ${ }^{3}$ ), only the $17-\mathrm{Kda}$ antigen in the marmoset species. All of the chimpanzee strains behaved like the larger serocluster $A$ of $U$. urealyticum (chimpanzee strain 13863 shown), but the antigens from the canine strain had modified $M_{r}$ values of 16.5 and $17.5 \mathrm{Kda}$.

\section{Urease activity}

Figs. $3 a$ and $3 b$ show gels stained with lead acetate for detection of enzymic activity. Fig. 3a shows the pattern of 'native' ureaplasmal ureases after electrophoresis on a $7 \cdot 5 \% \mathrm{w} / \mathrm{v}$ gel when SDS was not present either in the gel or in the buffer. Under these conditions, no accurate assessment of $\mathbf{M}_{r}$ is possible. Fig. $3 b$ shows the same 'native' ureases after electrophoresis on a $7.5 \% \mathrm{w} / \mathrm{v}$ gel with SDS in the gel and in the buffer. Although $M_{r}$ estimations are not necessarily accurate under these conditions, both bands were within the 170 $200 \mathrm{Kda}$ range. Displayed in fig. 3 are the results for $U$. urealyticum, serotypes 1, 5, 9 and 13, and for the ureaplasmal strains of non-human origin.

Immunoblots of the denatured enzyme (fig. 4) show that the larger $72-\mathrm{Kda}$ inactive urease subunit ${ }^{7}$ is recognised by MAb UU8/17 only in the human (serotype 8) feline, marmoset and chimpanzee blots. It should be noted, however, that this sub-unit was not detected on immunoblots of denatured urease from $U$. urealyticum serotypes 3, 6 and 14 by this technique.

The urease enzyme 'catch test' was performed with strains of serotypes of $U$. urealyticum and the ureaplasmas of non-human origin. Separate tests were performed in the wells of 96-well microtitration plates coated with different anti-urease MAbs, each recognising a distinct epitope on the enzyme. The results obtained are shown in the table. Earlier competition assays ${ }^{7}$ had suggested that MAb UU8/ 1 recognised the same epitope as that recognised by UU8/17. However, whilst the urease of the $U$. diversum, canine, feline and marmoset strains was not recognised by UU8/1, it was recognised by UU8/17. This may suggest the presence of at least five epitopes on the enzyme. In the non-human ureaplasmas, the urease of the chimpanzee isolates alone possesses, or has available, five distinct epitopes of $U$. urealyticum urease. 
a

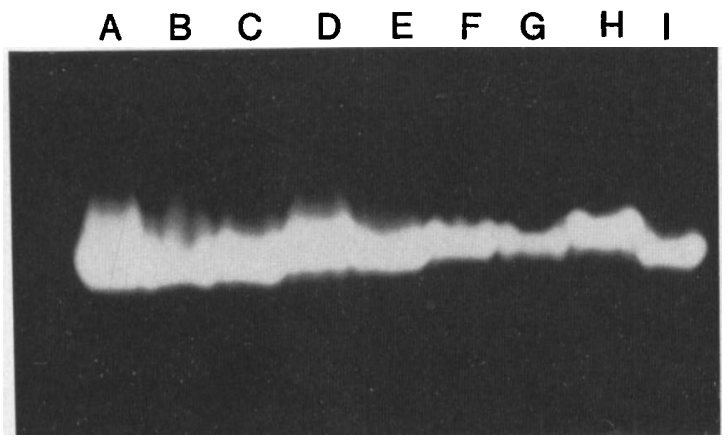

Fig. 3a. Detection of 'native' ureaplasmal ureases with $0 \cdot 1 \mathrm{M}$ lead acetate after electrophoresis on a $7.5 \% \mathrm{w} / \mathrm{v}$ gel without SDS in either gel or buffer. Lane A, feline strain; B, $U$. diversum (T44); C, canine strain; D, marmoset strain; E, chimpanzee strain (13863); F, U. urealyticum serotype $9 ; \mathbf{G}, U$. urealyticum serotype $13 ; \mathbf{H}, U$. urealyticum serotype $1 ; \mathbf{I}, U$. urealyticum serotype 5 .

b

A $\quad B \quad C \quad D \quad E \quad F \quad G \quad H ~ I$

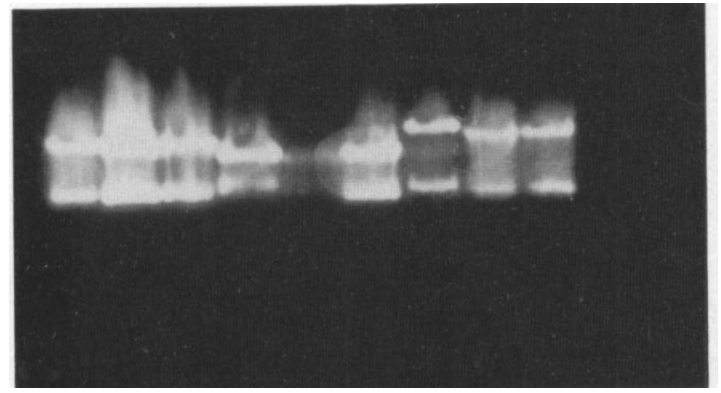

Fig. 3b. Detection of 'native' ureaplasmal ureases with $0.1 \mathrm{M}$ lead acetate after electrophoresis on a $7.5 \% \mathrm{w} / \mathrm{v}$ gel with SDS in both gel and buffer. Lane $\mathbf{A}, U$. urealyticum serotype 5; $\mathbf{B}$, chimpanzee strain (13863); C, marmoset strain; D, canine strain; E, U. diversum (T44); F, feline strain; G, U. urealyticum serotype $1 ; \mathbf{H}, U$. urealyticum serotype $13 ; \mathbf{I}, U$. urealyticum serotype 9 .

\section{Discussion}

For logistical reasons, in this comparative study, apart from the five chimpanzee ureaplasmal strains and three $U$. diversum strains, only single ureaplasmal strains from each of the other animal species were compared with five serotypes of $U$. urealyticum. The latter included four serotypes from serocluster A and one serotype from serocluster B. Similar results were obtained throughout with the five chimpanzee strains and with the three strains of $U$. diversum. Although the data should be

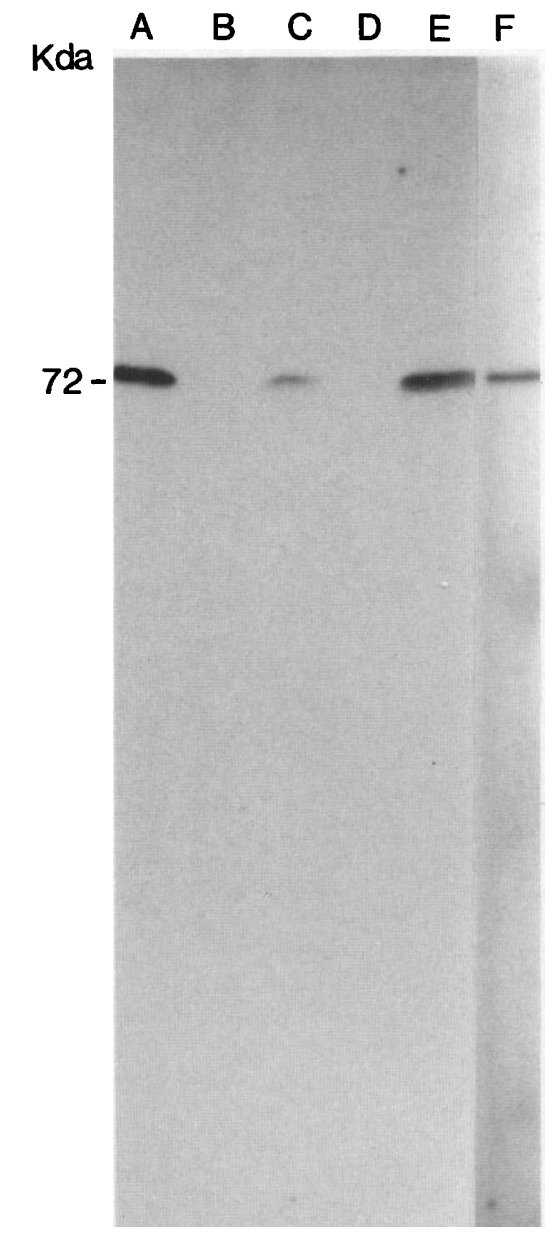

Fig. 4. Immunoblots of denatured ureases of ureaplasmal strains with MAb UU8/17 and ${ }^{125}$ I-labelled Protein A. Lane A, $U$. urealyticum serotype $8 ; \mathbf{B}, U$. diversum (T44); C, feline; D, canine; E, marmoset; F, chimpanzee (13863). SDS-PAGE was performed on a $15 \% \mathrm{w} / \mathrm{v}$ gel. (Composite figure from two immunoblots, both original gels incorporated $\mathrm{M}_{\mathrm{r}}$ markers.)

regarded as of a preliminary nature and meriting further investigation of a larger number of strains of non-human origin, several features have emerged. The $96-\mathrm{Kda}$ antigen, which is $U$. urealyticum serotype 8-specific, possesses epitopes which are not expressed in any of the animal strains examined. All four MAbs recognising distinct epitopes on this polypeptide gave similar results with each ureaplasmal strain.

One or both antigens of the $16 / 17-\mathrm{Kda}$ antigen doublet, or these in a slightly modified state (canine strain), appear to be shared throughout ureaplasmal species. Whereas the chimpanzee strains and the $U$. urealyticum strains of serocluster A behaved similarly, only the $16-\mathrm{Kda}$ antigen was present in 
Table. Distribution of urease epitopes among some human and non-human ureaplasmas determined by the urease 'catch test'

\begin{tabular}{l|ccccc}
\hline & \multicolumn{5}{c}{ Urease epitope recognised by MAb } \\
\cline { 2 - 6 } \multicolumn{1}{c|}{ Ureaplasma strains } & UU8/1 & UU8/12 & UU8/16 & UU8/17 & UU8/25 \\
\hline U. urealyticum serotypes 1, 5, 8,9,13 & +++ & +++ & +++ & +++ & +++ \\
Chimpanzee ureaplasmas (5 strains) & +++ & +++ & +++ & +++ & +++ \\
Feline ureaplasma & - & - & +++ & +++ & + \\
Marmoset ureaplasma & - & + & +++ & +++ & +++ \\
U.diversum (3 strains) & - & + & +++ & +++ & ++ \\
Canine ureaplasma & - & + & +++ & + & ++ \\
\hline
\end{tabular}

- , Negative reaction; + to +++ , increasing positivity of reaction.

the $U$. diversum and feline strains and only the 17$\mathrm{Kda}$ antigen in the $U$. urealyticum serocluster B strain and the marmoset strain. Although both antigens were detected in the canine strain, their apparent $\mathbf{M}_{\mathrm{r}}$ were modified. The apparent absence of even low levels of either the $16-$ or $17-\mathrm{Kda}$ antigens in some ureaplasmal strains indicates that these are distinct polypeptides sharing a common epitope rather than one antigen being a modification of the other.

In the non-denaturing gel system, the 'native' urease was detected in all ureaplasmas. Variations in apparent $M_{r}$ may be due to the gel system used or may reflect minor variations in amino-acid sequence, structure or organisation of this enzyme. Such $M_{r}$ variations of the urease from serotypes of $U$. urealyticum have been reported previously. ${ }^{14}$

The enzyme 'catch test' was used with antiurease MAbs that had been shown to recognise four distinct epitopes on the enzyme from $U$. urealyticum. In addition, MAb UU8/1 was used because, although it appeared to recognise the same epitope as UU8/17, it had earlier given a result with competition assays that needed clarification. Comparison of the results from the human and chimpanzee strains with those from the other animal ureaplasmal strains indicates that UU8/1 recognises a fifth distinct epitope. The results indicate that there are differences in the organisation of urease from different species or that there may be minor variations in primary structure. In some species, given epitopes may not be expressed or there may be a different three-dimensional folding of the enzyme such that epitopes are not available for recognition.

Apart from the absence of the 96-Kda antigen, the chimpanzee ureaplasmal strains alone behaved similarly to those of $U$. urealyticum serotypes of serocluster $\mathrm{A}$. This is consistent with the finding of Mouches et al. ${ }^{5}$ that the ureaplasmas of the chimpanzee are more related in polypeptide patterns to $U$. urealyticum serocluster A than are ureaplasmas of other non-human species. The chimpanzee may thus provide the most appropriate model for study of $U$. urealyticum infection. The marmoset strain, like $U$. urealyticum serotype 1 (serocluster B), but unlike those strains from other non-human species, appears to possess only a $17-\mathrm{Kda}$ antigen, this again being consistent with the suggestion of Mouches et al. ${ }^{5}$ that ureaplasmas isolated from marmosets differed from those of other animal species.

It may be noted that, in our results, the ureaplasmal strains from the different non-human hosts are distinguishable on the combined basis of the presence or absence of the 16- and 17-Kda (or slightly modified) antigens and of those epitopes readily recognised on the urease (table). This raises the question of whether this apparent correlation might have a more general application, whereby the species of origin of any non-human ureaplasmal strain might be determinable by such combinations of the urease 'catch tests' and immunoblotting with the MAb probe. However, such an application must remain speculative until similar urease 'catch' tests and immunoblotting (rather than abbreviated methods, e.g., dot-blot) to confirm antigen distributions already shown with the few test strains, have been performed with many more strains from each of the host sources, especially those of nonhuman origin.

This work was supported by a grant from the British Technology Group. 


\section{REFERENCES}

1. Robertson J A, Stemke G W. Expanded serotyping scheme for Ureaplasma urealyticum strains isolated from humans. J Clin Microbiol 1982; 15: 873-878.

2. Stemke G W, Robertson J A. Problems associated with serotyping strains of Ureaplasma urealyticum. Diagn Microbiol Infect Dis 1985; 3: 311-320.

3. Thirkell D, Myles A D, Russell W C. Serotype 8- and serocluster-specific surface-expressed antigens of Ureaplasma urealyticum. Infect Immun 1989; 57: 1697-1701.

4. Howard C J, Gourlay R N, Collins J. Serological comparison between twenty five bovine ureaplasma (T-mycoplasma) strains by immunofluorescence. Int $J$ Syst Bacteriol 1975; 25: 155-159.

5. Mouches C, Taylor-Robinson D, Stipkovits L, Bove J M. Comparision of human and animal ureaplasmas by one and two-dimensional protein analysis on polyacrylamide slab gel. Ann Microbiol (Paris) 1981 ; 132B: 171196.

6. Barile M F. DNA homologies and serological relationships among ureaplasmas from various hosts. Pediatr Infect Dis 1986; 5: S296-S299.

7. Thirkell D, Myles A D, Precious B L et al. The urease of
Ureaplasma urealyticum. J Gen Microbiol 1989; 135 : 315-323.

8. Dulbecco R, Vogt M. Plaque formation and isolation of pure lines with poliomyelitis viruses. J Exp Med 1954; 99: 167.

9. Mautner V, Wilcox H N A. Adenovirus antigens: a model system in mice for sub-unit vaccination. $J$ Gen Virol $1974 ; 25: 325-336$.

10. Precious B L, Thirkell D, Russell W C. Preliminary characterization of the urease and a $96 \mathrm{kDa}$ surfaceexpressed polypeptide of Ureaplasma urealyticum. J Gen Microbiol 1987; 133: 2659-2670.

11. Myles A D. Molecular characterisation of Ureaplasma urealyticum. PhD Thesis, St Andrews University, 1989.

12. Russell W C, Blair G E. Polypeptide phosphorylation in adenovirus-infected cells. J Gen Virol 1977; 34: 19-35.

13. Shaik-M M B, Guy A L, Pancholy S K. An improved method for the detection and preservation of urease activity in polyacrylamide gels. Anal Biochem 1980; 103: $140-143$.

14. Davis J W, Ahn C, Villanueva I. Enzyme differences in serovar clusters of Ureaplasma urealyticum and Ureaplasma diversum. Abstract from the 7th International Congress of Mycoplasmology 1988: p 41. 